\title{
A maternidade no contexto do cárcere: uma revisão sistemática
}

\section{The motherhood in the imprisonment context: a systematic review}

\section{La maternidad en el contexto carcelario: una revisión sistemática}

\author{
Sabrina Daiana Cúnico* \\ Pontifícia Universidade Católica do Rio Grande do Sul - PUC-RS, Porto Alegre, Rio \\ Grande do Sul, Brasil
}

\section{Marina Valentim Brasil**}

Pontifícia Universidade Católica do Rio Grande do Sul - PUC-RS, Porto Alegre, Rio Grande do Sul, Brasil

\section{Mariana Barcinski***}

Pontifícia Universidade Católica do Rio Grande do Sul - PUC-RS, Porto Alegre, Rio Grande do Sul, Brasil

\begin{abstract}
RESUMO
Este estudo teve como objetivo realizar uma revisão sistemática em bases de dados internacionais de artigos publicados entre 2003 e 2014, sobre a maternidade no cárcere. Os resultados evidenciaram a coexistência de estudos que vincularam ideais conservadores, associados à maternidade, e daqueles que problematizaram a diferença entre a versão ideológica da maternidade e a série de perdas e problemas que compõem a vida real das mulheres privadas de liberdade. De acordo com os estudos revisados, nos parece evidente que a maternidade no contexto de encarceramento assume contornos específicos e diversos daquela maternidade exercida fora das grades da prisão. Embora a maternidade seja importante, problematizamos o foco exclusivo neste aspecto da identidade feminina quando falamos nas possibilidades de ressocialização de mulheres encarceradas. Ao focar exclusivamente na maternidade, as instituições prisionais reforçam os estereótipos de gênero da sociedade mais ampla, entendendo as mulheres unicamente como mães. Nesse sentido, chamamos a atenção para que os esforços para a ressocialização considerem as outras esferas na vida destas mulheres, tais como o trabalho e a educação, de modo a favorecer a emancipação e a autonomização das mulheres pós-encarceramento.
\end{abstract}

Palavras-chave: gênero, prisão, maternidade.

\section{ABSTRACT}

This study was aimed at carrying out a systematic review based on international database of published articles between 2003 and 2014. The 
results proved the coexistence of studies which linked conservative ideals associated to motherhood, to those which questioned the difference between the ideological view of motherhood and the various losses and problems which make up the real life of women deprived of freedom. According to the reviewed studies, it seems evident to us that motherhood in the context of imprisonment takes a new and distinct shape from that lived out of prison. Although motherhood is important, we question the exclusive focus on this aspect of female identity when talking about the possibilities of incarcerated women's rehabilitation. By focusing solely on motherhood, prison institutions reinforce gender stereotypes of the broader society, understanding women only as mothers. In this sense, we draw attention to the importance for rehabilitation efforts to consider other spheres in these women's lives, such as work and education, in order to promote the emancipation and autonomy of women post-incarceration.

Keywords: gender, prison, motherhood.

\section{RESUMEN}

Este estudio tuvo como objetivo realizar una revisión sistemática en bases de dados internacionales de artículos publicados entre 2003 y 2014, sobre la maternidad en la cárcel. Los resultados evidenciaron la coexistencia de estudios que vincularon ideales conservadores asociados a la maternidad y aquellos que problematizaron la diferencia entre la versión ideológica de la maternidad y la serie de perdidas y problemas que componen la vida real de las mujeres privadas de libertad. De acuerdo con los estudios revisados, nos parece evidente que la maternidad en el contexto de encarcelación asume contornos específicos y diversos de aquella maternidad ejercida fuera de las barras de la prisión. Por mas que la maternidad sea importante, problematizamos el foco exclusivo en este aspecto de identidad femenina cuando mencionamos las posibilidades de resocialización de mujeres presas. Al concentrarse exclusivamente en la maternidad, las instituciones penitenciarias refuerzan los estereotipos de genero de la sociedad mas amplia, entendiendo a las mujeres únicamente como madres. En este sentido, llamamos la atención para que los esfuerzos de resocialización consideren a las otras esferas en la vida de estas mujeres, tales como el trabajo y la educación, de modo que favorezca la emancipación y la autonomizacion de las mujeres post-encarcelamiento.

Palabras clave: gênero, prisión, maternidad.

\section{Introdução}

De acordo com os dados do Ministério da Justiça, entre 2007 e 2012 houve um crescimento de $42 \%$ na população prisional feminina, que atingiu o índice de mais de 35.000 mulheres encarceradas (Brasil, 2012). Embora a população feminina seja pequena se comparada à masculina, é inegável que ela representa um número significativo dentro do contexto carcerário (Cerneka, 2009). Assim, considerando que o sistema penal brasileiro e mundial foi criado por homens e para homens, foi o aumento da criminalidade e do encarceramento feminino que trouxe à tona questões antes não pensadas pelo sistema jurídico e prisional (Matos \& Machado, 2007). 
No Brasil, embora o aprisionamento de mulheres em salas, celas e alas afastadas dos homens já acontecesse, foi somente a partir da década de 40 que, com o Código Penal, foi regulamentado que as penas impostas às mulheres fossem cumpridas em estabelecimentos que tivessem a finalidade única de encarcerar mulheres (Mello, 2014). No entanto, em nível nacional somente 79 estabelecimentos prisionais dos 1.478 existentes são exclusivos para mulheres (Brasil, 2012). No estado do Rio Grande do Sul, por exemplo, até o ano de 2010 havia somente um estabelecimento prisional exclusivamente destinado às mulheres (Bitencourt, 2012). Atualmente, no mesmo estado quatro dos 98 estabelecimentos prisionais são exclusivamente femininos, sendo dois localizados na cidade de Porto Alegre, capital do estado, um em Guaíba, região metropolitana de Porto Alegre e um em Torres, litoral do estado.

Por mais que as motivações para o crime, os tipos de delitos cometidos e a experiência na prisão para homens e mulheres sejam diferentes, a situação da mulher no cárcere ainda parece ser tratada a partir de tentativas de adaptações do sistema já existente e não vista, sob a ótica de gênero, de acordo com as suas particularidades (Cerneka, 2009; Colares \& Chies, 2010; Matos \& Machado, 2007). No contexto prisional, contudo, questões como a gestação e a maternidade exigem uma reflexão mais profunda sobre o impacto do encarceramento na vida das mulheres. Assim, a falta de estruturas específicas para a custódia das mulheres grávidas e as indagações sobre a permanência dos filhos com as mães na prisão são pontos que ganham notoriedade nesta discussão. Sobre esta última questão, de um lado há quem argumente por esta necessidade de amparo e de formação de vínculo entre mãe e bebê. De outro, há quem defenda que a prisão é um ambiente insalubre e por isso impróprio para crianças (Mello, 2014).

De acordo com a Constituição Federal Brasileira e com o Estatuto da Criança e do Adolescente (ECA) é dever do Estado assegurar à mulher presa as condições para que possa permanecer com seus filhos durante o período de amamentação (Brasil, 1988; 1990). Para que este direito seja assegurado às mães privadas de liberdade, a Lei de Execuções Penais (LEP) estabelece, em seu artigo 83, que todos os estabelecimentos penais destinados às mulheres sejam dotados de berçários para que elas possam cuidar e amamentar seus filhos até, no mínimo, seis meses de idade. 0 artigo 83 da referida Lei menciona que:

"... a penitenciária de mulheres será dotada de seção para gestantes e parturiente e de creche para abrigar crianças maiores de 6 (seis) meses e menores de 7 (sete) anos, com a finalidade de assistir a criança desamparada cuja responsável estiver presa" (Brasil, 1984). 
Entretanto, segundo dados do Ministério da Justiça, apenas 27,45\% das prisões exclusivamente femininas do Brasil contêm espaços específicos para a custódia de gestantes e 19,61\% possuem berçários ou estruturas separadas das galerias comuns. Sendo assim, quando a mulher presa que não está em alguma destas unidades e está próxima do nono mês de gestação, ocorre a transferência desta para um estabelecimento com melhor estrutura, o que pode dificultar o contato com a família em função da distância (Brasil, 2008). Vale mencionar que tais dados podem ter sofrido variações ao longo nos últimos anos, uma vez que o último relatório contendo a consolidação dos dados fornecidos pelos estados brasileiros a respeito das mulheres encarceradas data de 2008.

Para além das discussões sobre a permanência ou não dos bebês junto às suas mães no ambiente prisional, entendemos que a própria experiência da maternidade no cárcere deve ser discutida. Assim, questões como o que é ser mãe na prisão e quais as representações e os eventuais privilégios associados às mães neste contexto configuram-se como temas relevantes nesta discussão. Considerando tais apontamentos, o objetivo deste estudo foi realizar uma revisão sistemática sobre a maternidade no contexto do cárcere, a fim de identificar qual o panorama de publicações sobre a temática, assinalando particularmente o que vem sendo produzido a partir de uma abordagem de gênero.

Para Scott (1995), o termo gênero remete às construções sociais que discorrem sobre os papéis adequados aos homens e às mulheres. Desta forma, gênero pode ser caracterizado como um elemento fundado sobre as diferenças entre os sexos, além de um modo de dar significado às relações de poder. Assumir uma abordagem de gênero é, portanto, adotar uma postura crítica na análise da igualdade e da diferença, demarcando uma nova perspectiva de interpretação e mudança da realidade social (Araújo, 2005).

\section{Método}

De modo a identificar os estudos referentes à vivência da maternidade em instituições prisionais, dois juízes independentes conduziram uma revisão sistemática nas bases de dados Scopus, PsycInfo e Redalyc. A busca foi realizada no mês de maio de 2014. A Scopus é uma base multidisciplinar de resumos e de fontes de informação de nível acadêmico. A Psycinfo é uma base de dados em Psicologia, Educação, Psiquiatria e Ciências Sociais, sendo editada pela American Psychological Association (APA). Já a base Redalyc é uma rede de revistas científicas com acesso aberto da América Latina e do Caribe, Espanha e Portugal, de responsabilidade da Universidade 
Autónoma do Estado do México (UAEM). As bases acima citadas foram escolhidas em função da sua representatividade e por possuírem um alto grau de abrangência, facilitando a procura por artigos relacionados à temática. A busca nas bases foi realizada utilizando a string "prison AND motherhood", "female prisons AND motherhood", "correctional institutions AND motherhood" e "incarceration AND motherhood". A busca inicial resultou em 74 estudos. Após a exclusão de 13 estudos repetidos nas bases, restaram 61 referências potencialmente relevantes.

Os estudos foram então analisados a partir dos seguintes critérios de inclusão: ser artigo científico, versar sobre a experiência da maternidade no cárcere e estar disponível na íntegra, em português ou inglês no período de 2003 a 2014. Quarenta e cinco deles não atenderam a estes critérios, sendo, portanto, excluídos. Os 16 estudos restantes foram analisados a partir dos critérios de exclusão, a saber: ter como foco a dependência química ou doença mental nas mulheres presas ou priorizar a discussão a respeito da criminalidade feminina, não focando na experiência da maternidade. A partir desses critérios, cinco estudos foram removidos, restando 11 artigos no banco de dados final. O procedimento de busca é apresentado na figura 1. 


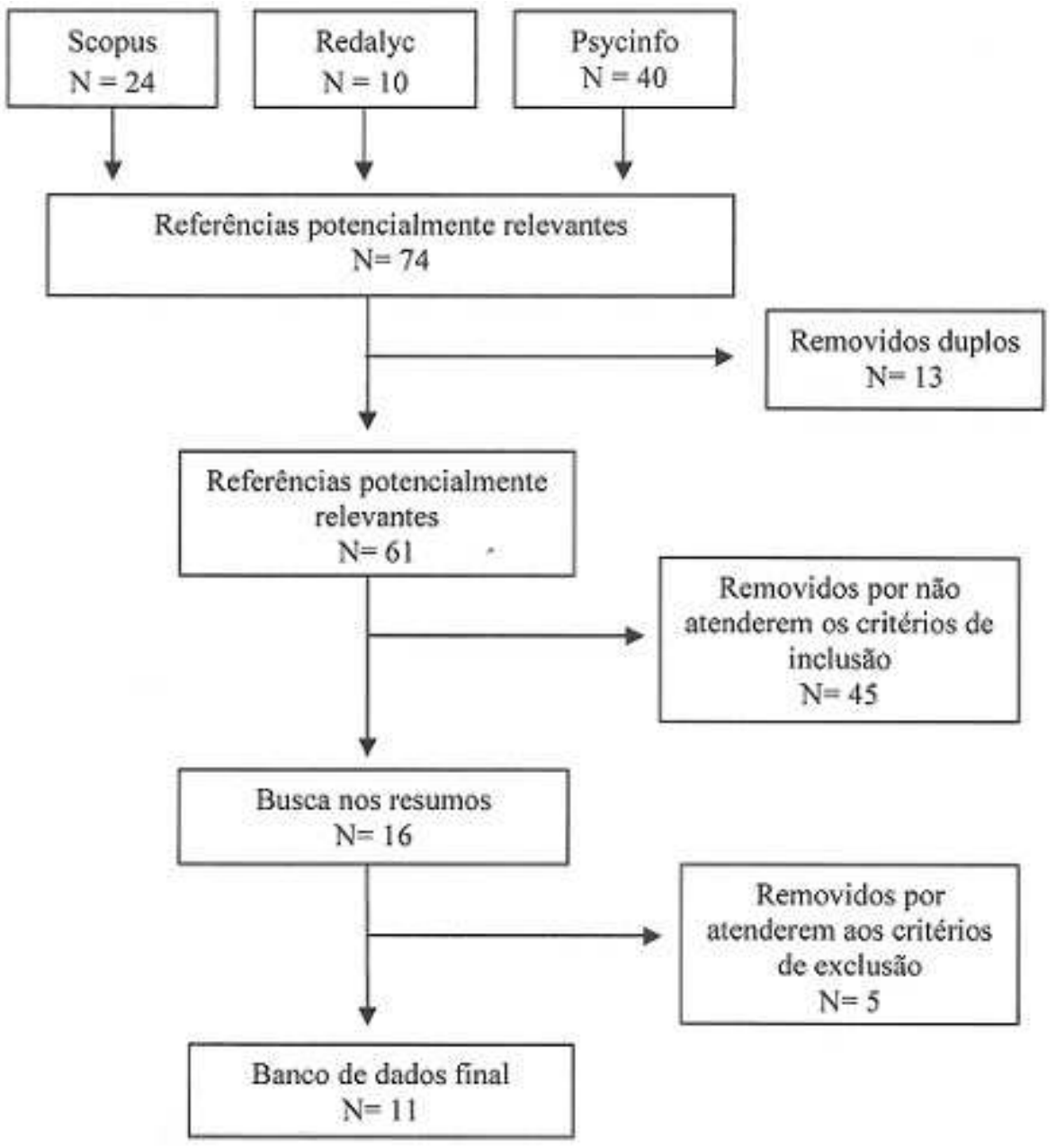

Figura 1: Estratégia de busca

Os dados dos 11 artigos foram extraídos e alocados em uma planilha do Excel, que incluía o nome do estudo, nome dos autores, ano e país de publicação, delineamento e perfil dos participantes. Tais componentes são apresentados de forma sintetizada na Tabela 1. 
Sabrina Daiana Cúnico, Marina Valentim Brasil, Mariana Barcinski

Tabela 1. Descrição de características dos estudos revisados

\begin{tabular}{|c|c|c|c|c|}
\hline Nome & Autor/Ano & Pais & Delineamento & $\begin{array}{c}\text { Perfil dos } \\
\text { Participantes }\end{array}$ \\
\hline $\begin{array}{l}\text { Pondering the discourse } \\
\text { of prison mamas: a } \\
\text { research note }\end{array}$ & Forsyth (2003) & $\begin{array}{l}\text { Estados } \\
\text { Unidos }\end{array}$ & $\begin{array}{l}\text { Estudo } \\
\text { qualitativo } \\
\text { realizado por } \\
\text { meio de } \\
\text { entrevistas }\end{array}$ & $\begin{array}{l}24 \text { mulheres } \\
\text { encarceradas que } \\
\text { cram măes; } 4 \\
\text { profissionais da } \\
\text { instituiçąo }\end{array}$ \\
\hline $\begin{array}{l}\text { Maternidade atrás das } \\
\text { grades: comportamento } \\
\text { parental em contexto } \\
\text { prisional }\end{array}$ & $\begin{array}{l}\text { Serras \& Pires } \\
\quad(2004)\end{array}$ & Portugal & $\begin{array}{l}\text { Estudo } \\
\text { qualitativo } \\
\text { realizado por } \\
\text { meio de } \\
\text { entrevistas }\end{array}$ & $\begin{array}{l}6 \text { mulheres } \\
\text { encarceradas que } \\
\text { eram màes }\end{array}$ \\
\hline $\begin{array}{l}\text { Criminalized mothers: } \\
\text { The value and devaluation } \\
\text { of parenthood from } \\
\text { behind bars }\end{array}$ & $\begin{array}{l}\text { Moe \& Ferraro } \\
\text { (2006) }\end{array}$ & $\begin{array}{l}\text { Estados } \\
\text { Unidos }\end{array}$ & $\begin{array}{l}\text { Estudo } \\
\text { qualitativo } \\
\text { realizado por } \\
\text { meio de } \\
\text { entrevistas de } \\
\text { história de vida }\end{array}$ & $\begin{array}{l}30 \text { mulheres } \\
\text { encarceradas que } \\
\text { eram màcs }\end{array}$ \\
\hline $\begin{array}{l}\text { Motherhood starts in } \\
\text { prison: the experiences of } \\
\text { motherhood among } \\
\text { women in prison }\end{array}$ & $\begin{array}{c}\text { Shamai \& Kochal } \\
\qquad(2008)\end{array}$ & Israel & $\begin{array}{l}\text { Estudo } \\
\text { qualitativo } \\
\text { realizado por } \\
\text { meio de } \\
\text { entrevistas em } \\
\text { profundidade }\end{array}$ & $\begin{array}{l}9 \text { mulheres que } \\
\text { eram mães, que } \\
\text { estavam em } \\
\text { periodo de } \\
\text { reabilitação } \\
\text { obrigatório pós } \\
\text { encarceramento }\end{array}$ \\
\hline $\begin{array}{l}\text { Reentry and } \\
\text { renegotiating motherhood: } \\
\text { Maternal identity and } \\
\text { success on parole }\end{array}$ & $\begin{array}{l}\text { Brown \& Bloom } \\
\qquad(2009)\end{array}$ & $\begin{array}{l}\text { Estados } \\
\text { Unidos }\end{array}$ & $\begin{array}{l}\text { Estudo } \\
\text { quantitativo e } \\
\text { qualitativo }\end{array}$ & $\begin{array}{l}25 \text { mulheres } \mathrm{cm} \\
\text { condicional que } \\
\text { eram màes }\end{array}$ \\
\hline $\begin{array}{l}\text { Vivèncias da maternidade } \\
\text { em uma prisão feminina } \\
\text { do Estado do Rio Grande } \\
\text { do Sul }\end{array}$ & $\begin{array}{l}\text { Mello \& Gauer } \\
\text { (2011) }\end{array}$ & Brasil & $\begin{array}{l}\text { Estudo } \\
\text { qualitativo } \\
\text { realizado por } \\
\text { meio de } \\
\text { entrevistas } \\
\text { semiestruturadas }\end{array}$ & $\begin{array}{l}31 \text { mulheres } \\
\text { presas em ala } \\
\text { materno-infantil } \\
\text { de instituiçào } \\
\text { prisional }\end{array}$ \\
\hline $\begin{array}{c}\text { Correctional } \\
\text { administrators' } \\
\text { perceptions } \\
\text { of prison nurseries }\end{array}$ & $\begin{array}{c}\text { Campbell \& } \\
\text { Carlson (2012) }\end{array}$ & $\begin{array}{l}\text { Estados } \\
\text { Unidos }\end{array}$ & $\begin{array}{c}\text { Estudo } \\
\text { qualitativo } \\
\text { realizado através } \\
\text { de entrevistas via } \\
\text { telefonema }\end{array}$ & $\begin{array}{c}28 \\
\text { administradores } \\
\text { de presidios } \\
\text { americanos }\end{array}$ \\
\hline $\begin{array}{l}\text { Anchoring amongst the } \\
\text { waves: Discursive } \\
\text { constructions of } \\
\text { motherhood and addiction }\end{array}$ & $\begin{array}{l}\text { Kilty \& Dej } \\
\quad(2012)\end{array}$ & Canadá & $\begin{array}{l}\text { Estudo } \\
\text { qualitativo } \\
\text { realizado por } \\
\text { meio de } \\
\text { entrevistas de } \\
\text { histórias de vida }\end{array}$ & $\begin{array}{c}22 \mathrm{ex}- \\
\text { presidiárias }\end{array}$ \\
\hline $\begin{array}{l}\text { The significance of } \\
\text { breastfeeding to } \\
\text { incarcerated pregnant } \\
\text { women: An exploratory } \\
\text { study }\end{array}$ & $\begin{array}{c}\text { Huang, Atlas \& } \\
\text { Parvez (2012) }\end{array}$ & $\begin{array}{l}\text { Estados } \\
\text { Unidos }\end{array}$ & $\begin{array}{l}\text { Estudo } \\
\text { qualitativo } \\
\text { realizado por } \\
\text { meio de } \\
\text { entrevistas }\end{array}$ & $\begin{array}{l}20 \text { gestantes } \\
\text { encarceradas }\end{array}$ \\
\hline $\begin{array}{l}\text { Motherhood as } \\
\text { punishment: The case of } \\
\text { parenting in prison }\end{array}$ & Haney (2013) & Estados Unidos & $\begin{array}{l}\text { Estudo } \\
\text { qualitativo, } \\
\text { realizado através } \\
\text { de uma pesquisa } \\
\text { etnográfica }\end{array}$ & $\begin{array}{l}\text { Mâes } \\
\text { encarceradas na } \\
\text { companhia de } \\
\text { seus fillhos }\end{array}$ \\
\hline $\begin{array}{l}\text { Is motherhood important? } \\
\text { Imprisoned women's } \\
\text { maternal experiences } \\
\text { before and during } \\
\text { confinement and their } \\
\text { postrelease expectations }\end{array}$ & $\begin{array}{c}\text { Barnes \& } \\
\text { Stringer (2014) }\end{array}$ & Estados Unidos & $\begin{array}{l}\text { Estudo } \\
\text { quantitativo } \\
\text { realizado por } \\
\text { meio de aplicaçĩo } \\
\text { de questionários }\end{array}$ & $\begin{array}{l}210 \text { màes } \\
\text { encarceradas }\end{array}$ \\
\hline
\end{tabular}




\section{Resultados}

Em relação ao delineamento, nove estudos utilizaram abordagens qualitativas em suas pesquisas, um priorizou uma abordagem quantitativo-qualitativa e um empregou método quantitativo para atingir os objetivos propostos. A maioria das pesquisas era proveniente dos Estados Unidos (sete), além do Canadá (um), Brasil (um), Israel (um) e Portugal (um).

Serras e Pires (2004) conduziram um estudo cujo objetivo foi construir uma teoria sobre o comportamento parental das mães encarceradas que têm junto de si os filhos na prisão, em uma instituição de Portugal. Por meio de entrevistas com mães que cumpriam pena judicial superior a um ano, os autores identificaram que o aspecto característico do comportamento parental destas mulheres foi a centralidade e a dedicação total às crianças, pois isto as ajudava a passar o tempo e a não pensar tanto na sua situação, suavizando os impactos da reclusão e tornando-a mais suportável. Os resultados apontaram também para a presença mínima dos pais, ou por também estarem presos ou pelas mulheres encarceradas já não terem qualquer tipo de relação com eles.

A mesma centralidade na relação mãe e filho foi apontada no estudo de Shamai e Kochal (2008), que teve como objetivo compreender o significado da maternidade para mulheres encarceradas e como estas vivenciavam o efeito do encarceramento no relacionamento com seus filhos durante e após o período de reclusão. Por meio de entrevistas em profundidade com nove mulheres ex-presidiárias que estavam em processo de reabilitação obrigatório à população carcerária israelense, os autores identificaram que a experiência na prisão, embora dolorosa, pode contribuir para uma melhoria no exercício do papel materno, mesmo nos casos em que a relação entre mãe e filho era problemática anteriormente ao encarceramento. Isto se dá pelo fato desta relação passar a ser foco central na vida emocional das mulheres presas.

Tal centralidade mostrou estar associada a um status especial do papel de mãe, socialmente valorizado, que seria importante para manejar um sentimento contínuo de fracasso - frequentemente vivenciado por estas mulheres -, mesmo para aquelas que não se consideravam boas mães antes do aprisionamento. Shamai e Kochal (2008) inferiram ainda que a sociedade tem interesse em reforçar esta representação positiva da maternidade na prisão, por entender que aquelas mulheres que buscam manter o contato com os filhos têm mais chances de reabilitação.

A valorização social da maternidade também esteve presente nos resultados da pesquisa americana de Moe e Ferraro (2006), que 
buscou compreender de que forma o status associado à maternidade interferia nas motivações das mulheres para o crime e auxiliaria no enfrentamento das dificuldades advindas do período de encarceramento. A partir de entrevistas realizadas com mães encarceradas, os autores identificaram que as responsabilidades maternas, especialmente aquelas relacionadas ao sustento dos filhos, são apontadas como motivadoras para a prática delituosa. $O$ estudo concluiu, ainda, que as mulheres consideravam o exercício da maternidade como um meio para aquisição de um status social valioso, sendo, portanto, altamente cobiçado. Ao falar de si mesmas como boas mães, elas pensavam em si próprias para além do ato criminoso, vendo-se como membros ativos e valiosos da sociedade a partir do desempenho da função de ser mães.

Também abordando o aspecto positivo da vivência da maternidade no cárcere tem-se o estudo de Mello e Gauer (2011), realizado com mulheres encarceradas em ala materno-infantil que estavam em companhia de seus filhos e gestantes de um presídio feminino do sul do Brasil. A pesquisa demonstrou em seus resultados que o filho pode ser uma estratégia para o enfrentamento da prisão e de minimização do sofrimento para as mães encarceradas. Ademais, as mulheres interpretaram o encarceramento como uma oportunidade de efetivamente exercerem o papel materno, além de reconhecerem que o foco na maternidade pode representar uma ferramenta para a interrupção do uso de drogas.

Da mesma forma que os autores anteriormente citados, o estudo de Kilty e Dej (2012) associou o abuso de substâncias com a maternidade. Os autores buscaram examinar como se dava, para mulheres ex-presidiárias canadenses que tinham uma vivência de uso problemático de drogas, a construção de suas identidades como mães à luz das dificuldades que enfrentavam em sua reabilitação. Buscaram, ainda, problematizar o uso das concepções tradicionais de maternidade como uma técnica de vigilância em mulheres que têm ou tiverem problemas com a lei.

Os resultados do referido estudo apontaram que, no contexto penal, as mães que não seguem um padrão normativo de maternidade são caracterizadas como preguiçosas e negligentes. Já as mães que usam drogas são vistas como imaturas, fora de controle e desviantes. Tais concepções que definem uma "má mãe" podem fazer com que as próprias mulheres reconheçam-se, efetivamente, como faltosas. 0 estudo também mencionou que a instituição prisional, ao orientar como as mães devem cuidar de seus filhos -, assumindo uma visão essencialista das funções maternas - as responsabilizavam pelo comportamento futuro de seus filhos. Dentro desta perspectiva, a intervenção da instituição seria legitimada, portanto, a partir do exercício de uma parentalidade supostamente deficiente. 
Neste mesmo viés, em que a maternidade pode se configurar como uma estratégia de controle institucional, Haney (2013), através de pesquisa etnográfica em um presídio na Califórnia que abrigava mulheres e seus filhos, buscou analisar de que forma a maternidade é conceitualizada e vivenciada neste contexto e compreender como ela pode se configurar como uma forma de controle para as encarceradas. Os resultados apontaram como aspecto significativo, a negação total da autoridade das mulheres para com seus filhos, uma vez que eram submetidas a regras e práticas infantilizadoras, não havendo espaço para que se tornassem figuras de autoridade para as crianças.

Também se configurou, na pesquisa de Haney (2013), como outro mecanismo institucional a restrição do direito à privacidade das mães no cuidado com seus filhos. Tal restrição fundamentava-se, segundo a autora, na crença de que o status de transgressoras legais destas mulheres pudesse se traduzir em uma transgressão no desempenho do papel materno. O estudo pontuou, ainda, que as prisões de mulheres que vivem com os filhos são caracterizadas por uma colisão de lógicas, em que a realidade institucional da punição se choca com o imperativo de cuidado. Além disso, as prisões reproduziriam em seu interior a representação da privacidade materna como prerrogativa de mulheres de classes privilegiadas. Segundo esta representação, as práticas de maternagem das mulheres pobres seriam de domínio e escrutínio público.

O estudo americano de Brown e Bloom (2009) teve como objetivo analisar as questões concernentes à maternidade como o primeiro desafio encontrado por mulheres em processo de reinserção na comunidade, propondo a ênfase da identidade materna no processo de reinserção social. O referido estudo foi conduzido por meio de entrevistas com 25 mulheres, mães, em liberdade condicional, selecionadas a partir de consulta a todas as fichas institucionais de liberdade condicional de mulheres no Havaí.

Os resultados da pesquisa supracitada apontaram que a maternidade, tradicionalmente considerada um direito natural das mulheres, é redefinida por elas como um privilégio que pode ser revogado a qualquer momento. Ademais, os autores identificaram que as mães recebem muito pouca preparação durante a prisão para enfrentar a vida após o cumprimento da pena, embora haja, no contexto americano, muitos programas relacionados à parentalidade. Os autores mencionam que tais programas nem sempre levam em consideração a realidade destas mulheres presas: pobreza e inúmeros problemas de relacionamentos, 0 que dificulta que coloquem em prática as "habilidades parentais" aprendidas na prisão. Apontando para os aspectos positivos do manejo da maternidade no contexto carcerário, Barnes e Stringer (2014) buscaram explicar, a partir da concepção de um indivíduo dotado de múltiplas identidades, 
a repercussão de salientar a identidade materna - em detrimento da identidade de presa, por exemplo - nos projetos futuros de mulheres encarceradas. O estudo realizado com 210 mães encarceradas em uma instituição americana teve como resultados que 0 bom relacionamento das mães com os cuidadores atuais de seus filhos, 0 contato regular com a família, a manutenção de um sentimento de pertença ao sistema familiar e a expectativa de recuperar a guarda dos filhos após o período de reclusão eram aspectos que fomentavam uma proeminência da identidade materna das encarceradas. Os autores concluem que a prevalência da identidade materna pode motivar as mães a buscar manter boas relações com seus filhos e com os demais familiares, configurando uma maior chance de reinserção na comunidade e de diminuição da possibilidade de reincidência.

Tal qual o estudo de Barnes e Stringer (2014), o modo com que a maternidade é vista como instrumento privilegiado para a ressocialização também se fez presente na pesquisa americana de Campbell e Carlson (2012). O estudo partiu da análise do entendimento e do grau de familiaridade de administradores de instituições prisionais com programas voltados à maternidade. Foram entrevistados administradores de oito estados americanos que possuíam tais programas e vinte administradores de estados que não os possuíam. Embora os resultados omitam as percepções acerca destes programas por parte dos administradores de prisões que os possuem, os autores crêem na existência de uma série de benefícios para seus participantes, tais como a diminuição da taxa de reincidência, o investimento na relação entre mãe e filho e o potencial encerramento do ciclo de encarceramento.

O estudo de Huang, Atlas e Parvez (2012) buscou analisar o entendimento, as crenças e as experiências acerca da amamentação para 20 gestantes encarceradas em um presídio nova-iorquino. Os resultados das entrevistas apontaram para três temas frequentes. 0 primeiro tema foi relacionado ao sentimento de incerteza sobre os planos de amamentação, causado pelo afastamento das mulheres do seu contexto social, familiar e cultural proporcionado pelo cárcere. As mães mostravam-se ansiosas e preocupadas com a posterior separação de seus filhos e por perderem a possibilidade de amamentar. Esta insegurança fazia com que elas inclusive planejassem encurtar o período de aleitamento, para evitar possíveis complicações para o desmame.

O segundo tema apontado pelo estudo de Huang, Atlas e Parvez (2012), referia-se ao sentido de "recomeço" que a maternidade significava para as entrevistadas. Planejar a amamentação representava a esperança de voltar para casa e ter a oportunidade de desempenhar o papel materno. O terceiro e último tema evidenciava a sensação que as entrevistadas já possuíam de "boa maternidade", 
por estarem planejando os aspectos práticos da amamentação, uma vez que este era o elemento que as identificava como mães e facilitava que se vissem neste papel. A amamentação marcava concretamente que os filhos teriam apenas uma mãe, o que se mostrou importante para estas mulheres que tiveram seus filhos cuidados por inúmeros indivíduos ao longo da vida.

Por fim, o estudo americano de Forsyth (2003) teve por objetivo examinar o discurso de mulheres presas em relação às suas atitudes e crenças sobre a maternidade. A partir da realização de entrevistas com mulheres privadas de liberdade e com profissionais que atuavam em uma instituição prisional, os resultados indicaram que as mulheres aprisionadas sofriam de uma "dupla punição": pelo confinamento em função do delito cometido e pela agonia advinda da realidade de serem mães encarceradas. Seus filhos, geralmente, estavam vivendo com algum membro da família, que frequentemente não era o pai. Embora todas as participantes tenham relatado que se preocupavam com os filhos, o autor pontuou a importância de analisar estes discursos dentro de um contexto institucional que reforça a maternidade como norma social.

\section{Discussão}

Dos 11 artigos selecionados para a revisão, cinco deles analisaram os resultados sob uma perspectiva de gênero (Brown \& Bloom, 2009; Haney, 2013; Kilty \& Dej, 2012; Moe \& Ferraro, 2006; Shamai \& Kochal, 2008). Compreender a maternidade no contexto do cárcere através da categoria de gênero é assumir uma postura crítica a respeito da visão que idealiza a estrutura conservadora da família, entendendo a maternidade como construto multidimensional que remete à diversidade cultural e de classe (Arendell, 2000). De modo geral, estes cinco artigos problematizaram a diferença entre a versão ideológica da maternidade e a série de perdas e problemas que compõem a vida real das mulheres privadas de liberdade, além de ponderarem sobre a utilização da maternidade como instrumento de regulação legal e social, especialmente no contexto do cárcere. Apesar das transformações vivenciadas pelas famílias nos últimos anos, estudos contemporâneos têm apontado para a prevalência da tradicional distinção dos papéis de mãe e de pai dentro do ambiente doméstico: o papel materno remetendo ao cuidado dos filhos e o paterno tendo a função de prover materialmente a família, além de envolver questões de disciplina e de exercício da autoridade (Narvaz \& Koller, 2006; Trindade \& Enumo, 2002). Embora se reconheça que diversas alterações culturais tenham modificado a compreensão sobre qual seria o lugar da mulher no contexto social, podemos afirmar que 
a maternidade ainda confere a ela um papel respeitável na sociedade (Pimentel, 2013; Ribeiro, 2007).

A afirmação da natural habilidade feminina para o exercício do papel materno pode significar o aprisionamento de muitas mulheres ao âmbito doméstico. Por outro lado, o fato da mulher ser considerada a única capaz de cuidar dos filhos e do espaço privado da casa faz com que the seja atribuído um poder que não é comum aos homens, definindo o ofício materno como um território exclusivo do gênero feminino. Assim, a partir deste papel prescrito - de cuidadora da família - , a maternidade assume um caráter de experiência fundamental ao sentimento de completude das mulheres (Barcinski, Capra-Ramos, Weber, \& Dartora, 2013; Narvaz \& Koller, 2006).

Cabe à mulher, então, o "sacrifício" e abnegação em nome da rede vincular que possui e que compete a ela mantê-la. E será através desta prescrição que ela, resignada ao seu papel de passividade, irá consolidar sua fonte de reconhecimento de si e diferenciar-se dos demais. A maternidade pode ser vista como um percurso de vida restritivo no que tange o papel social da mulher. Sendo ela - a maternidade - abastecida por ideais de mãe que muitas vezes não se tornam acessíveis às mulheres de classes sociais mais desfavorecidas, torna-se distante para elas a possibilidade de cumprir o papel de forma socialmente satisfatória. Ser mãe é assumir um papel que conecta a mulher intensamente com a responsabilidade de zelar pela intimidade familiar. Em nome disso, ela passa a ser subjugada e relegada estritamente a este fim. A mulher, sexualmente reprimida, tem na maternidade a possibilidade de "salvação" (Barcinski et al., 2013), aproximando-se a um papel que configura um ser recatado, pudico, submisso.

Aquelas que não cumprem adequadamente com o papel materno normativo podem vivenciar um sentimento de culpa e incapacidade (Narvaz \& Koller, 2006). Neste sentido, a mulher infértil, por exemplo, é comumente caracterizada como "triste e incompleta" (Trindade \& Enumo, 2002, p. 171), uma vez que algumas mulheres sentem que foram impedidas de vivenciar a realização própria da identidade feminina. No que se refere às representações sociais da mulher que vivencia a impossibilidade de gerar um filho, estas são atreladas às noções depreciativas de incompletude e inferioridade (Trindade \& Enumo, 2002). Portanto, é a partir da centralidade do papel materno como definidor do estatuto feminino que os estudos feministas problematizam a maternidade como uma armadilha social às mulheres.

Entendemos que a utilização da maternidade como um mecanismo de controle acontece dentro e fora do cárcere. No entanto, no contexto prisional estes mecanismos são mais explícitos, mais justificados e mais legitimados, em especial quando associados à possibilidade de ressocialização. A instituição prisão, em seus supostos esforços de 
ressocialização das mulheres privadas de liberdade, enfatiza a domesticidade feminina, especialmente a expectativa de que elas desejem retomar suas funções maternas. Nesse sentido, as mulheres em situação de prisão são culpabilizadas por não estarem desempenhando a função de mãe e por supostamente não terem pensado nos filhos no momento em que transgrediram. Elas passam, então, a ser vistas como violadoras tanto da lei quanto do comportamento prescrito ao gênero feminino (Barcinski, 2012).

Assim sendo, a ideia de recuperação das mulheres em conflito com a lei passa frequentemente pela confirmação de estereótipos de gênero como os relacionados ao desejo e a vivência da maternidade. No caso dos homens, por outro lado, a paternidade dificilmente é usada como reforço de "redenção". No caso da prisão masculina, é por meio do reforço do ideal de homem trabalhador que a ideia de recuperabilidade se sustenta (Miyamoto \& Krohling, 2012). Considerando tais aspectos, o conservadorismo da instituição prisional no que se refere à reprodução das expectativas sociais acerca dos papeis masculinos e femininos, fica evidente.

Ainda que através de métodos mais sutis de coerção e controle, é sobre o corpo do apenado que a prisão exerce o seu poder, docilizando e submetendo este corpo à sujeição constante de suas forças (Foucault, 1975/2004). Versando especificamente sobre as dinâmicas das instituições totais, Goffman (1996) afirma que os indivíduos em seu interior passam por um processo ininterrupto de "mortificação do eu" (p. 24). Após um processo de "despimento" identificatório que fere os indivíduos de inúmeras maneiras, estes necessitam se reorganizar e desenvolver ainda estratégias de resposta. É neste cenário que a maternidade pode atuar como uma ferramenta de auto-preservação e sobrevivência da própria identidade da mulher presa dentro de um contexto que tem como característica principal a destituição da individualidade de seus membros. A partir desta perspectiva, pode-se reconhecer nas mulheres encarceradas uma possibilidade de "revestirem-se" de uma forma poderosa e socialmente reconhecida: a do papel de mãe.

Portanto, é importante considerarmos que a maternidade, especialmente na prisão, pode assumir a função de empoderamento para as mulheres, cujo ideal de mãe permeia todo o processo identificatório, fazendo com que busquem nesta identidade a possibilidade de engajar-se a um ofício socialmente elevado. Por mais que a identidade materna restrinja a mulher à passividade e à repressão, ela representa simultaneamente a possibilidade de elevação a um status social privilegiado.

Em concordância com este entendimento, alguns dos estudos analisados nesta revisão, embora atentando para a utilização da maternidade como instrumento de controle, enfatizaram que é inegável o poder motivacional que a maternidade possui para as 
mulheres aprisionadas, mesmo para aquelas que não escolheram a maternidade e negligenciaram esta função anteriormente. Em outras palavras, o "ser mãe" pode ser vivenciado como uma fonte significativa de esperança durante o período de encarceramento (Brown \& Bloom, 2009; Shamai \& Kochal, 2008). Dentro desta perspectiva, por mais que a maternidade no cárcere possa ser vivenciada de forma dolorosa, pelas dificuldades inerentes ao próprio contexto do encarceramento, ela possui um valor para algumas mulheres que não pode ser desprezado.

Os outros seis artigos analisados nesta revisão elencaram, de modo geral, aspectos positivos quanto ao reforço da maternidade no contexto carcerário e os supostos benefícios alcançados com 0 incentivo do exercício da maternidade por parte da instituição (Barnes \& Stringer, 2014; Campbell \& Carlson, 2012; Forsyth, 2003; Huang, Atlas \& Parvez, 2012; Mello \& Gauer, 2011; Serras \& Pires, 2004). Alguns defenderam que, por mais que em um primeiro momento o status de presidiária possa parecer inconsistente com a maternidade, a prisão pode ser vista como uma oportunidade, para algumas mulheres, de resgatar ou construir sua identificação com a figura materna, visto que muitas delas já possuíam outros filhos, mas não mantiveram contato com eles em momento anterior ao aprisionamento (Forsyth, 2003; Mello \& Gauer, 2011).

Dentre estes seis, outros estudos enfatizaram o impacto que uma maternidade "deficiente" - em função da não amamentação ou da falta de vinculação entre mãe e filho - poderia ter no futuro dos filhos das mulheres encarceradas, justificando a relevância de uma intervenção preventiva (Campell \& Carlson, 2012; Huang, Atlas \& Parvez, 2012). Os demais assumiram o posicionamento de que quando o papel materno é reforçado, as mulheres demonstram maior motivação para manter um bom vínculo, não só com os filhos, mas também com os demais familiares fora da prisão. Assim, sugerem a importância de reforçar e ampliar o apoio às mulheres encarceradas, empoderando-as enquanto mães, uma vez que tal empoderamento refletirá em uma maior proteção das próprias crianças e trará benefícios para as comunidades (Barnes \& Stringer, 2014; Serras \& Pires, 2004).

A partir do exposto, percebe-se que os estudos que têm como foco central a maternidade no cárcere assumem uma perspectiva das mães como provedoras do bem-estar para a família, para a comunidade, para os filhos e para a instituição prisional. Sendo assim, questionamos a inexistência da ênfase dada aos benefícios que as próprias mulheres poderiam obter neste contexto de reforço da maternidade, uma vez que - tal como apresentado - os estudos parecem se focar somente nas vantagens que seriam externas a elas. Diante da argumentação aqui tecida e de acordo com os estudos revisados, nos parece evidente que a maternidade no contexto de 
encarceramento assume contornos específicos e diversos daquela maternidade exercida fora das grades da prisão. Embora atuando como um instrumento de regulação legal e social, os estudos revisados apontam, por exemplo, que a valorização da maternidade no contexto de privação de liberdade pode atuar como forma de manutenção dos vínculos existentes antes do aprisionamento. A ênfase no exercício do papel materno no contexto prisional assume ainda particular importância se considerarmos as mulheres como seres primordialmente relacionais (Cunha, 1994), sendo, portanto, a privação mais intensamente sentida por elas a das relações familiares (Almeida, 2006; Cunha, 1991).

Se para as mulheres, de modo geral, a maternidade se configura como uma experiência complexa, para aquelas que estão privadas de liberdade ela adquire nuances ainda maiores, o que faz com que dificilmente se enquadrem no personagem da mãe normativa. Isto porque o próprio ato transgressor que deu origem ao cárcere é visto como um ato egoísta, uma vez que acarretou na distância e na ausência forçada da mãe para com seus filhos. Sendo assim, a própria reclusão faz com que estas mulheres não alcancem o ideal do que é frequentemente associado à boa mãe.

Além disso, devemos reconhecer as especificidades do contexto social vivenciado pela maioria das mulheres em situação de prisão. De maneira geral, elas são provenientes de periferias urbanas, possuem baixa escolaridade e têm histórico de ruptura de vínculos familiares (Cerneka, 2009). Tais fatores certamente permeiam a maneira com que exercem a maternidade e quais expectativas nutrem em relação ao seu exercício.

Portanto, da mesma forma que a experiência da maternidade não é universal, sendo em grande parte determinada pelo contexto no qual ela se desenvolve, a crítica ao incentivo da maternidade também deve ser relativizada. Se a maternidade pode (e certamente é) configurar-se como um instrumento poderoso de regulação social, o incentivo ao seu exercício pode significar, para mulheres privadas de liberdade, um incremento em suas possibilidades de reinserção social e a melhoria da qualidade de vida no cárcere.

\section{Considerações finais}

O aumento do encarceramento feminino e o reconhecimento dos diversos atravessamentos implicados nesse fenômeno exigem uma reflexão mais profunda sobre as questões relacionadas à gestação e à maternidade no cárcere. O presente artigo procurou evidenciar qual é - estado atual de conhecimento sobre esta temática, a partir da realização de uma revisão sistemática da literatura PSI, a qual foi analisada sob uma perspectiva de gênero. Por mais que se tenha 
evidenciado a análise da frequente vinculação de ideais conservadores, envoltos na maternidade, houve espaço para os estudos que puderam contrapor as ideias tradicionais.

Impende mencionar que este estudo não tem a pretensão de reforçar os estereótipos associados ao exercício da maternidade, argumentando em favor de uma suposta habilidade natural das mulheres para exercer o papel materno. Problematizamos, sim, o desempenho da maternidade como única possibilidade de ressocialização feminina, bem como a exclusiva atenção à identidade materna quando teorizamos acerca das mulheres privadas de liberdade. Embora seja um aspecto importante, a maternidade não é o único campo comum entre as mulheres encarceradas - mesmo porque nem todas são mães - e, portanto, não é a única forma de fomentar aspectos que auxiliem no processo de ressocialização destas mulheres.

Ao focar exclusivamente neste aspecto da identidade feminina - a maternidade - as instituições prisionais reforçam os estereótipos de gênero da sociedade mais ampla, entendendo as mulheres unicamente como mães. Nesse sentido, chamamos a atenção para que os esforços para a ressocialização considerem as outras esferas na vida destas mulheres, tais como o trabalho e a educação, de modo a favorecer a emancipação e a autonomização das mulheres pósencarceramento. Como limitações do estudo, salientamos o fato deste ser um estudo teórico, composto por artigos que tratam de contextos sociais diversos e de experiências em sistemas prisionais diferentes, o que impede generalizações a respeito da maternidade e de sua complexidade no contexto prisional.

\section{Referências}

Almeida, V. P. (2006). Repercussões da violência na construção da identidade feminina da mulher presa: um estudo de caso. Psicologia: Ciência e Profissão, 26(4), 604-619.

Araújo, M. F. (2005). Diferença e igualdade nas relações de gênero: revisitando o debate. Psicologia Clínica, 17(2), 41-52.

Arendell, T. (2000). Conceiving and investigating motherhood: The decade's scholarship. Journal of Marriage and Family, 62(4), 1192-1207.

Barcinski, M. (2012). Expressões da homossexualidade feminina no encarceramento: o significado de se "transformar em homem" na prisão. Psico-USF, 17(3), 437-446.

Barcinski, M., Capra-Ramos, C., Weber, J. L. A, \& Dartora, T. (2013). O Marianismo e vitimização de mulheres encarceradas: formas alternativas do exercício do poder feminino. Ex aequo, (28), 87100. 
Barnes, S. L., \& Stringer, E. C. (2014). Is Motherhood Important? Imprisoned Women's Maternal Experiences Before and During Confinement and Their Postrelease Expectations. Feminist Criminology, 9(1), 3-23.

Bitencourt, A. H. (2012). Mulheres e sistema prisional: o sentido do trabalho para quem viveu e vive sob a égide do cárcere. Dissertação de Mestrado. Pontifícia Universidade Católica do Rio Grande do Sul, Porto Alegre, RS, Brasil.

Brasil. (1984). Lei de Execução Penal. Recuperado em 10 de junho, 2014, de: http://www.planalto.gov.br/ccivil_03/leis/l7210.htm

Brasil. (1988). Constituição da República Federativa do Brasil. Recuperado em 9 de junho, 2014, de: http://www.planalto.gov.br/ccivil_03/constituicao/constituicao. htm

Brasil. (1990). Lei $n^{\circ} 8.069$, de 13 de julho de 1990. Dispõe sobre o Estatuto da Criança e do adolescente e dá outras providências. Recuperado em 13 de julho, 2014, de: http://www.planalto.gov.br/ccivil_03/leis//8069.htm

Brasil. (2008). Ministério de Justiça. Departamento Penitenciário Nacional. Consolidação dos dados fornecidos pelas unidades da Federação. Mulheres encarceradas. Brasília, DF.

Brasil. (2012). Ministério da Justiça, Departamento Penitenciário Nacional. Infopen Estatística.Recuperado em 10 de agosto, 2014, de: http://www.mj.gov.br/depen

Brown, M., \& Bloom, B. (2009). Reentry and Renegotiating Motherhood: Maternal Identity and Success on Parole. Crime \& Delinquency, 55(2), 313-336.

Campbell, J., \& Carlson, J. R. (2012). Correctional Administrators' Perceptions of Prison Nurseries. Criminal Justice and Behavior, 39(8), 1063-1074.

Cerneka, H. A. (2009). Homens que menstruam: considerações acerca do sistema prisional às especificidades da mulher. Veredas do Direito, 6(11), 61-78.

Colares, L. B. C., \& Chies, L. A. B. (2010). Mulheres nas so(m)bras: invisibilidade, reciclagem e dominação viril em presídios masculinamente mistos. Revista Estudos Feministas, 18(2), 407-423.

Cunha, M. I. P. (1991). A prisão feminina como 'ilha de Lesbos' e 'escola do crime': discursos, representações, práticas. In Medeiros, C. L. (Org.). Do desvio à instituição total: subcultura, estigma, trajectos (pp. 163-184). Lisboa: Centro de Estudos Judiciários.

Cunha, M. I. P. (1994), Malhas que a reclusão tece. Questões de identidade numa prisão feminina. Lisboa: Gabinete de Estudos Jurídico-Sociais. 
Forsyth, C. J. (2003). Pondering the discourse of prison mamas: a research note. Deviant Behavior: An Interdisciplinary Journal, 24(3), 269-280.

Foucault, M. (2004). Vigiar e Punir: Nascimento da prisão (R. Ramalhete, Trad.). Petrópolis, RJ: Vozes. (Original publicado em 1975).

Goffman, E. (1996). Manicômios, prisões e conventos. (D. M. Leite. Trad.). Editora Perspectiva.

Haney, L. (2013). Motherhood as Punishment: The Case of Parenting in Prison. Women, Gender, and Prison: National and Global Perspectives, 39(1), 105-130.

Huang, K., Atlas, R., \& Parvez, F. (2012). The Significance of Breastfeeding to Incarcerated Pregnant Women: An Exploratory Study. Birth, 39(2), 145-155.

Kilty, J. M., \& Dej, E. (2012). Anchoring Amongst the Waves: Discursive Constructions of Motherhood and Addiction. Qualitative Sociology Review, 8(3), 6-23.

Matos, R., \& Machado, C. (2007). Reclusão e laços sociais: discursos no feminino. Análise Social, 40(185), 1041-1054.

Mello, D. C. (2014). Prisão feminina: gravidez e maternidade - um estudo da realidade em Porto Alegre - RS/Brasil e Lisboa/Portugal. Tese de Doutorado. Pontifícia Universidade Católica do Rio Grande do Sul, Porto Alegre, RS, Brasil.

Mello, D. C., \& Gauer, G. (2011). Vivências da maternidade em uma prisão feminina do estado do Rio Grande do Sul. Saúde e Transformação Social, 1(3), 113-121.

Miyamoto, Y., \& Krohling, A. (2012). Sistema prisional brasileiro sob a perspectiva de gênero: invisibilidade e desigualdade social da mulher encarcerada. Direito, Estado e Sociedade, 40, 223-241.

Moe, A. M., \& Ferraro, K. J. (2006). Criminalized mothers: the value and devaluation of parenthood from behind bars. Women \& Therapy, 29(3-4), 135-164.

Narvaz, M. G., \& Koller, S. H. (2006). Famílias e patriarcado: da prescrição normativa à subversão criativa. Psicologia \& Sociedade, 18(1), 49-55.

Pimentel, E. (2013). O lado oculto das prisões femininas: representações dos sentimentos em torno do crime e da pena. Latitude, 7(2), 51-68.

Ribeiro, F. B. (2007). Maternidades à margem: gravidez e nascimento numa instituição de proteção à infância. História: Questões \& Debates, 47, 139-155.

Scott, J. (1995). Gênero: uma categoria útil de análise histórica. Educação \& Realidade, 20(2), 71-99.

Serras, D., \& Pires, A. (2004). Maternidade atrás das grades: Comportamento parental em contexto prisional. Análise Psicológica, 22(2), 413-425. 
Shamai, M., \& Kochal, R. B. (2008). "Motherhood starts in prison": the experience of motherhood among women in prison. Family process, 47(3), 323-340.

Trindade, Z. A., \& Enumo, S. R. F. (2002). Triste e incompleta: uma visão feminina da mulher infértil. Psicologia USP, 13(2), 151182.

\section{Endereço para correspondência \\ Sabrina Daiana Cúnico}

Pontifícia Universidade Católica do Rio Grande do Sul

Av. Ipiranga, 6681, Prédio 11, $9^{\circ}$ andar, sala 937, Partenon, CEP 90619-900, Porto Alegre - RS, Brasil

Endereço eletrônico: sabrinacunico@yahoo.com.br

\section{Marina Valentim Brasil}

Pontifícia Universidade Católica do Rio Grande do Sul

Av. Ipiranga, 6681, Prédio 11, $9^{\circ}$ andar, sala 937, Partenon, CEP 90619-900, Porto

Alegre - RS, Brasil

Endereço eletrônico: marinavbr@hotmail.com

Mariana Barcinski

Pontifícia Universidade Católica do Rio Grande do Sul

Av. Ipiranga, 6681, Prédio 11, $9^{\circ}$ andar, sala 937, Partenon, CEP 90619-900, Porto Alegre - RS, Brasil

Endereço eletrônico: mariana.barcinski@pucrs.br

Recebido em: 30/10/2014

Reformulado em: 12/05/2015

Aceito para publicação em: 13/05/2015

\section{Notas}

* Doutoranda do Programa de Pós-Graduação em Psicologia da Pontifícia Universidade Católica do Rio Grande do Sul, Bolsista CAPES.

** Acadêmica de Psicologia da Pontifícia Universidade Católica do Rio Grande do Sul, Bolsista de Iniciação Científica Fapergs.

*** Professora doutora da Faculdade de Psicologia da Pontifícia Universidade Católica do Rio Grande do Sul. 